need have no terrors, for in addition to power alcohol, dyestuffs can be made with the aid of fungal organisms. $\quad \alpha$-Hydroxyanthroquinone pigments can be produced through the agency of certain species of the genus Helminthosporium. Ergosterol, fats and proteins must also be added to the list of mycologically producible substances, and the discovery by Chapman that a species of Oidium, found to be blocking sewer channels, could produce a thick film on nutrient medium, which had the odour and flavour of cream cheese, illustrates the romantic possibilities of science.

There is a great deal in Mr. Ramsbottom's address which can be used to render the acquirement of knowledge by the student a pleasant experience. The subject-matter is about candy, cheese, 'Marmite', coffee, mushrooms, baking and brewing-instances of common experience; but the discourse gave sufficient detail to make it of interest to the technician also. The dominant impression was one of confidence in the future. Natural mineral resources are now being exploited at an enormous rate, to produce power, dyestuffs and various chemicals; but many of these needs could also be met by the gentle ministrations of fungi. Perhaps the large number of substances already produced by these organisms might be taken as earnest that man need not fear the exhaustion of Nature's experiment with carboniferous conservation.

\title{
Genetics and Ecology in Relation to Selection
}

$\mathrm{O}^{\mathrm{NH}}$ NE of the most striking features of post-War biology has been the reanimation of Darwinism on a genotypic, instead of a phenotypic, basis. That such an attitude to evolutionary theory derives strong support from modern genetic and ecological work is undoubtedly the chief fact which emerged from the discussion on selection held on September 10 by Section D (Zoology) of the British Association at the recent Blackpool meeting. This occupied the first morning, and immediately followed Dr. J. S. Huxley's presidential address to the Section, which itself provided a comprehensive introduction to the subject. For his review of "Natural Selection and Evolutionary Progress" was a remarkable achievement, including almost everything that could and should be said in a general survey of selection.

In recent years experiment has largely replaced observation in the study of evolution. It is now plain that selection can operate only on genotypically controlled variability. Consequently, the effects of mutation, which is the initiation of a heritable variation, demand careful study. That these are nearly always disadvantageous need, however, cause us no surprise, for any organism must represent a system carefully balanced and adjusted to its environment ; so that any random change within it is immensely more likely to impair than to improve its efficiency. Yet occasional mutations have actually been observed which might be of advantage at least in special circumstances: like that mentioned by Dr. Huxley, in which a variety of tobacco failed to flower until the ratio of light to darkness was altered to correspond with what would prevail in a semi-tropical summer, when it proved superior to the normal form. But the relative viability of the genes may be most favourably compared in crowded cultures, when it can be studied as a deviation from expectation in Mendelian ratios. Dr. Timoféef-Ressovsky, who has elaborated this technique, pointed out that such tests also demon. strate that genes have different survival values in different degrees of crowding. For this work he has employed populations of Drosophila, and his method has provided an experimental basis for the study of selection in the laboratory.

Using the same genus, Dr. C. Gordon has now supplied proof of selective elimination in Nature. $\mathrm{He}$ finds that the number of autosomal recessives is very significantly in excess of the number of recessive sex-linked genes per length of chromatin -a discovery to be correlated with the fact that selection can operate on the former only when the genes in question are present in double dose, but on the latter, in every individual of the heterogametic sex in which they occur. Dr. Gordon has also demonstrated the reality of selection in Nature by releasing, and afterwards studying, a balanced population of Drosophila melanogaster. This consisted of normal and 'ebony' flies in a known ratio, set free in England, where the species is not indigenous. The latter is a dark mutant form, mono-factorial and recessive. It proved to be progressively eliminated in the open.

Selection, however, operates not merely to reject one character and conserve another: it may also alter the effects of the genes, but not the genes themselves. This view, the evolutionary implications of which have been developed only in recent years, follows naturally from the consideration that genetic factors interact with one another to produce the characters for which they are responsible. Thus mutations which are 
pathological in one gene-complex may be harmless or even advantageous in another, and such effects are open to the influence of selection. This concept, ably elaborated in Dr. Huxley's address, was illustrated by Mr. E. B. Ford by an example drawn from work on Gammarus chevreuxi. A gene which changed the eye-colour from black to red at one mutation, changed it to brownish when it mutated in another stock. A mating between the two showed that the same locus was concerned. Furthermore, successive back-crossings of each type of red into the other stock reversed their effects, demonstrating that the phenotypic difference was due to the action of the total genecomplex, not to mutation to another allelomorph at the same locus.

The effects of the genes, then, are susceptible of modification by selection, and Mr. Ford pointed out that the evolution of polymorphic mimics can be explained by no other means. It is often found that two forms of mimetic butterflies, each highly adapted in a number of distinct characters, are controlled by a single factor-pair. The allelomorphic difference concerned must have originated spontaneously by mutation, but we cannot suppose that selection has had to wait for the fortuitous occurrence of a change producing all the characters required. Such would seem an almost impossible event even in a single instance, yet the condition is common. The alternative explanation of the occurrence of parallel variation in model and mimic is disposed of by the superficiality of the resemblances between them. Thus Mr. Ford has found that the red pigment produced by the mimetic forms of Papilio polytes is chemically different from that of the models, though this is well known to be an instance in which the polymorphism concerned is under simple Mendelian control.

Furthermore, the study of mimetic insects has clearly demonstrated the reality of selection as an agent in stabilizing the population. Prof. G. D. Hale Carpenter, who discussed the forms of Pseudacrcea eurytus, which mimics various species of Bematistes, has collected this butterfly on an island in Lake Victoria in which the proportion of models to mimics varied in different years. He found that when the models were the commoner (70 per cent of the association), intermediates between the different forms of $P$. eurytus were rare (4 per cent or less); but when the mimics were in excess, such intermediates were quite frequent (11-30 per cent).

Finally, Darwin's view of sexual selection has evoked much criticism. It is rightly felt that his analysis of this subject is one of the least satisfactory steps in his argument. However, Mr. F. C. Minns provided evidence of sexual selection in budgerigars. He further pointed out that in some forms the process must favour vigour and activity in the male and the reverse in the female, a condition proved in Drosophila.

It was the duty of Prof. H. J. Muller to summarize the whole subject, and he performed this difficult task with success. There can be no doubt about the value of a carefully pranned discussion such as this, illuminating, as it did, a single problem from widely different angles. Each of the speakers has himself worked on the particular aspect of selection which he developed, and took the opportunity to bring forward recently ascertained or unrecorded facts.

\section{Obituary}

\section{Dr. W. H. Harrison}

$\mathrm{W}$ $\mathrm{E}$ regret to record the very sudden death, on August 18, of William Hudson Harrison, late of the Indian Agricultural Service, at his home near Leeds. Harrison was born in 1876. He graduated with honours in chemistry at the Yorkshire College in 1897, having been highly distinguished as a student and personally beloved by all. After graduation he was appointed chemist and manager at Knostrop Sewerage Works, Leeds, which post he held for nine years, receiving the warmest appreciation for his work both from the Leeds authorities and from the Royal Commission on sewage disposal.

In 1906 Harrison was appointed agricultural chemist to the Government of Madras, India. Here he commenced work by carrying out some valuable soil surveys, and then went on to a study of rice cultiva- tion as practised in India under swamp conditions. $\mathrm{He}$ discovered the most obscure phenomena, and proceeded to elucidate them step by step. His work was highly original and practical and is assuredly a classic in this field. His papers are a record of his resource and genius. For his earuer papers on this subject he was awarded the D.Sc. degree of the University of Manchester.

Harrison's extensive work on swamp soils can only be referred to here in mere outline. His preliminary observations showed that the anærobic fermentation of soil organic matter and green manure in these submerged soils produced large quantities of methane and nitrogen and relatively small amounts of carbon dioxide and hydrogen. On the other hand, anærobic fermentation of green manure without soil to hold up the gas produced much earbon dioxide and 